FRBSF Working Paper \#2003-07

\title{
Currency boards, dollarized liabilities, and monetary policy
}

\author{
credibility $^{1}$ \\ Mark M. Spiegel Diego Valderrama \\ Federal Reserve Bank of San Francisco, 101 Market Street, San Francisco, CA, 94105, USA
}

\begin{abstract}
The recent collapse of the Argentine currency board raises new questions about the desirability of formal fixed exchange rate regimes in moderndeveloping economies. This paper examines the impact of dollarized liabilities with potential default for a currency board with costly abandonment We compare the performance of a currency board to a central bank with full discretion in two environments: One with only idiosyncratic firm shocks, and one with both idiosyncratic shocks and shocks to the dollar-euro rate. We show that the possibility of default with peso-valued exports generates a risk premium on borrowing tied to expected future monetary policy. In addition, the presence of dollarized liabilities mitigates the time-inconsistency problem faced by the monetary authority. Finally, our numerical results demonstrate that the relative performance of the central bank under discretion compared to a currency board is ambiguous with only firm shocks, but that discretion unambiguously dominates when we also introduce shocks to the dollar-euro rate.
\end{abstract}

JEL classification: F31; F32; F34

Keywords: Currency board; Default; Dollarized liabilities

\footnotetext{
${ }^{1}$ This paper was prepared for the "Regional and International Implications of the Financial Instability in Latin America" conference at the University of California, Santa Cruz. The views expressed in this paper are those of the authors and not necessarily those of the Board of Governors of the Federal Reserve or the Federal Reserve Bank of San Francisco.
} 


\section{Introduction}

The recent collapse of the Argentine currency board has resulted in renewed attention on this form of exchange rate regime. Prior to this event, many had argued that "intermediate" exchange rate regimes had fallen out of favor [e.g. Frankel et al. (2001)], with pure floats or hard pegs, such as formal currency board arrangements, dominating them in terms of economic performance. The dra matic collapse of the Argentine economy raises new questions about the desirability of currency boards in modern developing economies.

The historical evidence on the empirical performance of currency boards suggest that they do have a disciplinary effect on policy and have tended to be successful. Ghosh et al (2000) report that exits from currency boards have been very rare. ${ }^{2}$ Moreover, currency board countries exhibit lower inflation, lower fiscal deficits, and lower average rates of monetary growth.

While exits from currency boards are rare, pegged exchange rate regime collapses are not. The prevalent pattern observed in the literature is that when fixed exchange rate regimes do collapse, their collapses tend to be “...messy and costly" (Edwards, 2002). For example, Edwards and Edwards (1987) report that Chilean GNP fell by 19 percent in 1982 subsequent to their devaluation, after accounting for terms of trade changes. Downturns of this magnitude are not uncommon following exchange rate collapses.

Given the experience with pegged regime collapses, it appears likely that when currency board collapses do occur, they would be even more disruptive. The historical record of currency board safety is likely to induce agents to feel free to denominate contracts in local and hard currencies interchangeably, leaving widespread potential for currency mismatches

\footnotetext{
${ }^{2}$ Ghosh et al. (2002) report a number of incidents where countries moved from currency boards to hard pegs at prevailing rates subsequent to independence, but such regime changes appear to have modest immediate real economic impacts.
} 
in the wake of a currency board collapse. That of course has been the experience with Argentina. From 1999 through 2002, GDP per capita in Argentina fell by over 50 percent while unemployment rose to 23 percent.

One notable feature of Argentina's collapse is the contribution of weakness in its financial sector. De la Torre et al (2003) note that while Argentina's currency board led to increased financ ial deepening in that country, it did so at the expense of greater financial fragility. Because a currency board left open the opportunity to devalue at some cost, it left Argentina exposed to expectations of devaluations and "sudden stops" in capital inflows. These sudden stops led to widespread disintermediation and financial turmoil.

Subsequent to devaluation, problems were particularly acute among agents facing dollar-denominated liabilities. A number of recent papers [e.g. Calvo and Reinhart (2002), Aghion et al. (2001)] have argued that using an exchange rate devaluation to respond to an adverse shock can be counterproductive in the presence of dollarized liabilities. While devaluations can have a positive impact on export performance, they may also have an adverse impact on domestic balance sheet positions. These adverse balance sheet effects may then exacerbate economic downturns if production is dependent on extrernal funds, as in Edwards and Vegh (1997).

There is ample empirical evidence that the dollarization of liabilities in the financial sector has exacerbated the adverse effect of devaluations. For example, Edwards and Edwards (1987) argue that Chile's financial liberalization prior to the 1982 crisis encouraged its financial conglomerates to increase their dependence on foreign dollar-denominated liabilities. The result was widespread bankruptcy subsequent to the 1982 devaluation.

Much of the recent theoretical work comparing exchange rate regimes has centered on examining the impact of dollarized liabilities in macro models with explicit financial channels. Caballero and Krishnamurthy (2001) examine a model where private agents hold 
sub-optimal levels of hard assets, as they underestimate the true social value of hard assets in the future. Chang and Velasco (2000) and Céspedes et al. (2001) examine models in which banks are exposed to runs under a variety of different exchange rate regimes. Their analysis tends to favor flexible exchange rate regimes over pegged regimes, but plausible conditions also exist that favor the fixed regimes.

In this paper, we examine the relative performance of a currency board in the presence of a banking sector with dollarized liabilities. We introduce a three-period model in which firms must borrow externally to finance their investments. To set up the balance sheet problem, we assume that while liabilities are in dollars, firm output is valued in pesos.

Moreover, we assume that the value of firm assets and liabilities move in opposite directions as a result of an exchange rate change. In the event of a devaluation, output values increase in pesos, but decrease in dollars.

We compare the performance of a currency board to a full discretionary regime in two environments: First, we allow the firms to face only idiosyncratic shocks to firm value. In this case, standard debt contracts can be motivated in terms of a Townsend (1979) model of borrowing with monitoring costs. Second, we also allow for the presence of an aggregate shock. To highlight the question of the merits of a currency board, we specify the shock as being to the hard currency exchange rate. Again, assuming that liabilities are denominated in dollars and output is denominated in pesos, we take the euro as the numeraire of world value. We can then examine the implications of a shock to the dollar-euro exchange rate.

Our results for the idiosyncratic risk only model suggest that the relative desirability of a currency board is ambiguous and dependent on the relative weight the centralbank places on consumption and inflation. For low consumption weights, the discretion regime generally dominates, although the difference appears to be small. However, for high consumption weights, the currency board dominates. 
The discretion regime's dominance in terms of the central bank loss function increases when we allow for foreign exchange rate shocks. In the presence of foreign exchange shocks, the discretion model is expected to dominate for all relative consumption weights in our simulations. This discrepancy represents the added value of adjustment in an environment that includes aggregate shocks. In particular, we find that the dominance of the discretion model over the currency board is greatest when the first-period realization of the dollar is high. Given this high realization, our numerical solution shows that under discretion the central bank chooses to smooth the first-period consumption effects of the dollar appreciation by letting the value of the domestic currency depreciate. This channel is of course unavailable within the currency board regime.

The relatively strong performance of the discretion regime over the currency board is is driven in part by the fact that the central bank under discretion considers the impact of exchange rate devaluations on the balance sheet positions when making its policy decisions. Dollarized liabilities mitigate the central bank's time-inconsistency problem, much like the accumulation of debt in the corporate finance literature can mitigate agency problems between corporate managers and their shareholders [e. g. Jensen (1986)]. ${ }^{3}$ These results follow Drazen and Masson (1994), who demonstrate that monetary policy can affect persistent fundamentals, and thereby affect future outcomes. In our model, the fundamental carried over into period 2 is the country's debt burden. This is higher under discretion, and leads the central bank to choose less depreciation than it would under the currency board in that period.

The remainder of this paper is dividedinto five sections. Section 2 sets up the model with idiosyncratic shocks only. The equilibrium of this model is discussed and numerically

\footnotetext{
${ }^{3}$ In a domestic context, Dennis (1999) has demonstrated that introducing a cost of inflation generally, but not universally, reduces a central bank's inflation bias.
} 
solved in section 3. Section 4 introduces shocks to the dollar-euro rate into this model and numerically solves for the equilibrium. Section 5 concludes.

\section{A Simple Model with Borrowing in Dollarized Liabilities}

\subsection{Setup}

We examine a small open-economy. There are two types of tradable goods in the model, Southern and Northern. The country only produces Southern goods, using a technology that requires the input of the Northern good initially and then produces the Southern good for two periods. The liabilities incurred in this borrowing are assumed to be "dollarized," i.e. denominated in dollars. There are three types of agents in the model, domestic entrepreneurs/firms, foreign investors, and a domestic central bank. Foreign investors are assumed to be risk neutral, while the loss functions of both the representative entrepreneur and the central bank are specified below.

The timing of the model is shown in Figure 1: There are three periods, indexed by $t=0,1,2$. There is a unit measure of domestic firms that are small and identical ex-ante, and are endowed with a technology that requires an input of 1 dollar's worth of foreign capital prior to the beginning of period 1. Firms are assumed to have no Northern goods in period 0 , and therefore must borrow 1 dollar from abroad. Plants yield output at the ends of periods 1 and 2 , and are then worthless.

There are two realizations of firm uncertainty. The first occurs between periods 0 and 1, after which the central bank chooses the first-period exchange rate, $e_{1}$. At the end of period 1, the firm then makes its default decision on its first-period loan. If the firm defaults, it is liquidated. If the firm services its first-period debt, it chooses first-period consumption and the fraction of outstanding debt to retire, and borrows to finance the remainder. The second realization of uncertainty occurs between periods 1 and 2, after which the central bank 
chooses $e_{2}$, the second period exchange rate. Finally, at the end of period 2, the entrepreneur makes its default decision on its second-period loan and consumes.

Firm/entrepreneur utility satisfies

$$
U_{i}=\log \left(C_{i 1}\right)+\beta \log \left(C_{i 2}\right)
$$

where $\beta$ represents one over the representative entrepreneur's discount rate, $0 \leq \beta \leq 1$, and $C_{i t}$ represents consumption of an individual firm in period $t$. We assume that entrepreneurs insure against their idiosyncratic consumption risk, so that we can drop the $i$ subscripts.

To keep the model tractable, we assume that there are 2 possible realizations of the idiosyncratic shocks, good $(g)$ and bad $(b)$, where $g>b$. The probability of a good shock is $1-\pi$ and the probability of a bad shock is $\pi$, where $0 \leq \pi \leq 1$. Below, we demonstrate that the profit maximizing solution for foreign investors is to liquidate the firms receiving the adverse shocks and to relend to the firms receiving the good shocks.

We introduce a role for nominal values to have real effects by positing that an unexpected depreciation of the domestic exchange rate increases the value of firm output in pesos, but decreases firm value in dollars. ${ }^{4}$ The initial assumption implies a commitment problem for the central bank, while the latter assumption implies that devaluations will reduce the firm's debt capacity so that liability dollarization has real effects.

Given these assumptions, we define peso-value output as

$$
Y_{i t}=A\left(\hat{e}_{t}\right) z_{i t} ; \quad z_{i t}=g, b ; \quad t=1,2 \text {. }
$$

where $z_{i t}$ represents firm $i^{\prime} s$ productivity shock in period $t$ and $\hat{e}_{t}$ represents the unanticipated change in the peso exchange rate, $\hat{e}_{t}=e_{t}-E_{t-1}\left(e_{t}\right)$, where $E_{t-1}\left(e_{t}\right)$ represents the expected value of $e_{t}$ in period $t-1, A[\cdot] \leq \bar{A}, A^{\prime}>0$ and $A^{\prime \prime} \leq 0$ for $A<\bar{A}$. The value of

\footnotetext{
${ }^{4}$ These real effects are likely to reflect p rice rigidities, as are modeled explicitly in Céspedes et al. (2000).
} 
period $t$ output in dollars then satisfies $\left(e_{t}\right)^{-1} Y_{i t} . A^{\prime}>0$ reflects the assumption that unanticipated devaluations increase output value in pesos. Given (2), the following restriction ensures that nominal devaluations reduce output value in dollars

$$
A^{\prime}\left(\hat{e}_{t}\right)<\left(e_{t}\right)^{-1} A\left(\hat{e}_{t}\right)
$$

for $A \leq \bar{A}$, which we adopt.

Foreign investors are risk neutral and competitive, and have access to unlimited funds at the world rate of interest, which we set to zero without loss of generality. We model decisions in terms of a representative foreign investor. We assume that firm output is only observable by the foreign investor after engaging in costly monitoring activities, so that a standard debt contract is optimal The contract extends one dollar to the entrepreneur in period 0 and requires him to pay a fixed amount, $d_{1}$, in dollars at the end of the first period. If the entrepreneur services his first-period debt obligations, no monitoring takes place. However, if the entrepreneur fails to service his contractual debt obligations, monitoring takes place at a fixed cost of $\delta$ in dollars and the foreign investor seizes the firm.

Between periods 0 and 1 , the central bank chooses $e_{1}$. There are then $1-\pi$ firms with output in dollars equal to $\left(e_{1}\right)^{-1} A\left(\hat{e}_{1}\right) g$ and $\pi$ firms with output in dollars equal to $\left(e_{1}\right)^{-1} A\left(\hat{e}_{1}\right) b$. The foreign investor then extends new funds equal to $l_{2}$ in dollars to the individual firm under a debt contract that calls for a fixed payment in dollars, $d_{2}$, at the end of period 2. We restrict the parameters such that the optimal strategy of the foreign investor is to extend no new lending to firms receiving the bad shock, while firms receiving the good shock obtain new funds and avoid default. We derive the restriction necessary for attainment of this separating equilibrium in the appendix. 
Since $d_{1}$ is common across all firms, the first-period budget constraint faced by firms receiving good shocks satisfies

$$
e_{1}\left(l_{2}-d_{1}\right) \geq C_{1}-A\left(\hat{e}_{1}\right) g \text {. }
$$

The central bank loss function is assumed to be decreasing in aggregate firm utility and quadratically increasing in expected inflation, proxied by depreciation of the peso exchange rate. The loss function of the central bank therefore satisfies

$$
L=-\theta \sum_{i} U_{i}+\left(e_{2}-e_{0}\right)^{2}
$$

where the exogenous term $\theta$ represents the relative weight of the central bank on utility.

Between periods 1 and 2, there is a second realization of idiosyncratic shocks, after

which then central bank chooses $e_{2}$. There are $(1-\pi)^{2}$ firms that received the good shock in the second-period. Under the separating equilibrium, the central bank takes as given that only these firms will be solvent at the end of period 2 . These firms then service their outstanding debt obligations and the remainder is consumed.

\section{Equilibrium with only idiosyncratic shocks}

\subsection{Equilibrium values under discretion}

We first solve the model under discretion. To ensure sub-game perfection, we solve the model backwards. Aggregate second-period consumption therefore satisfies

$$
C_{2}=(1-\pi)^{2}\left[A\left(\hat{e}_{2}\right) g-e_{2} d_{2}\right] .
$$

The central bank minimizes (5) subject to the choice of $e_{2}$ and (6). Under rational expectations, $\hat{e}_{2}=0$ in equilibrium. The central bank solution for $e_{2}$ satisfies

$$
e_{2}=e_{0}+\theta \beta(1-\pi)^{2} \frac{\left[A^{\prime}(0) g-d_{2}\right]}{2 C_{2}}
$$


To give the central bank an inflationary bias, we assume that $A^{\prime}(0) g-d_{2}>0$ in the neighborhood of $e_{2}$. This assumption implies that surprise devaluations can increase secondperiod consumption in pesos. ${ }^{5}$ Given this assumption, note that $e_{2}$ is increasing in $\theta$, the relative weight that the central bank places on second-period consumption.

The second period exchange rate, $e_{2}$, is also a function of $d_{2}$, the firm's dollarized liability. A necessary and sufficient condition for $\partial e_{2} / \partial d_{2} \leq 0$ is $A(0) \geq e_{2} A^{\prime}(0)$, which we adopt. This restriction implies that increases in dollarized liabilities are associated with reduced exchange rate depreciation, as the central bank avoids devaluation to ease the dollarized debt service burden of the representative surviving firm.

We next solve for the debtor's second-period contractual debt obligation, $d_{2}$. Recall that prior to the end of the first period, there are $(1-\pi)$ solvent firms that borrow $l_{2}$ in new dollar loans. With probability $\pi$, these firms will receive a bad shock in the second-period and default. In this case, the foreign investor will receive $\left(e_{2}\right)^{-1} A(0) b-\delta$ in dollars. With probability $(1-\pi)$, the firm will receive the good shock in the second period and service its outstanding debt obligation, $d_{2}$. Given new lending equal to $l_{2}$ and a 0 world interest rate, the risk-neutral creditors' zero-profit condition satisfies

$$
d_{2}=\left(\frac{1}{1-\pi}\right) l_{2}-\left(\frac{\pi}{1-\pi}\right)\left[\left(e_{2}\right)^{-1} A(0) b-\delta\right],
$$

subject to firms being solvent in the second period conditional on getting the good shock, which requires $d_{2} \leq\left(e_{2}\right)^{-1} A(0) g$.

\footnotetext{
${ }^{5}$ Although the impact of surprise devaluations is positive at the time of the central bank decision, it is negative ex-ante due to rational expectations. This conflicts with the literature, e.g. Cespedes et al. (2001) that finds that discretionary regimes may outperform pegged regimes ex-ante. This limitation is alleviated below, however, as our introduction of foreign shocks raises the possibility that devaluations may be expansionary ex-ante as well.
} 
There are two factors that determine the difference between lending, $l_{2}$, and contractual payments, $d_{2}$. The first is a default premium that covers expected monitoring costs, which is always positive. The second is an exchange risk premium, which reflects the effect of $e_{2}$ on collateral values. The latter premium can be either positive or negative, depending on whether the exchange rate is expected to appreciate or depreciate.

Equations (7) and (8) allow us to solve for $e_{2}$ and $d_{2}$ as a function of $l_{2}$. We demonstrate in the appendix that $\partial d_{2} / \partial l_{2}>0$ and $\partial e_{2} / \partial l_{2}<0$. The latter result reflects the impact of dollarized liabilities on the central bank's second-period monetary policy. When setting $e_{2}$, the central bank incorporates the adverse impact of a devaluation in $e_{2}$ on the peso cost of servicing the nation's dollarized liabilities. Through this channel, dollarized liabilities have the beneficial effect of mitigating the central bank's time-inconsistency problem.

We next turn to first-period values. Firms receiving the good shock in period 1 choose $C_{1}$ to maximize their expected utility, defined in (1), subject to (4), the second-period values derived above, and the outsta nding debt obligation $d_{1}$. Due to the creditors' zero profit condition, $d_{1}$ satisfies

$$
d_{1}=(1-\pi)^{-1}-\pi(1-\pi)^{-1}\left[\left(e_{1}\right)^{-1} A(0) b-\delta\right]
$$

The firms' first-order condition satisfies

$$
C_{1}=\frac{e_{1} C_{2}}{\beta(1-\pi) e_{2}} \text {. }
$$

We next solve for the central bank's first-period decision. When the central bank confronts its decision, there are $(1-\pi)$ firms that received the good shock. A share $\pi$ of these firms will go bankrupt in the second period, so that $(1-\pi)^{2}$ firms will receive good 
shocks in both periods and avoid bankruptcy. The central bank chooses $e_{1}$ to minimize its expected loss function in (5). Its first-order condition satisfies

$$
-\theta\left[\left(C_{1}\right)^{-1} \frac{\partial C_{1}}{\partial e_{1}}+\beta\left(C_{2}\right)^{-1} \frac{\partial C_{2}}{\partial e_{1}}\right]+2\left(e_{2}-e_{0}\right) \frac{\partial e_{2}}{\partial e_{1}}
$$

The solutions for $\partial C_{1} / \partial e_{1}, \partial C_{2} / \partial e_{1}$, and $\partial e_{2} / \partial e_{1}$ are in the appendix. Given solutions for $e_{2}$ and $C_{2}$ above, equations (10) and (11) then form a system of two equations in two unknowns, $C_{1}$ and $e_{1}$. We solve this system numerically below.

\subsection{Equilibrium Values Under a Currency Board}

We next turn to the solution of the model under a currency board regime. Currency boards usually maintain institutional rigidities designed to ensure the integrity of the pegged exchange rate regime. In response, some of the literature [e.g. Chang and Velasco (2000)] models currency boards as pegged regimes with perfect commitment. However, the recent Argentine experience implies that even though the abandonment of a currency board is likely to be very costly, it can happen with positive probability. It would therefore be incorrect to specify a currency board as possessing complete commitment.

However, c urrency boards do seem to universally last for some finite period of time. In practice, this may reflect the fact that the costs of abandoning a currency board are decreasing over time. Without modeling the source of this development explicitly, we posit a framework similar to that used by Rivera-Batiz and Sy (1997) and Oliva et al. (2001). We characterize a currency board as an exchange rate peg that can only be abandoned at a presumably large cost in the first period, but can be adjusted at no cost in the second period. ${ }^{6}$

\footnotetext{
${ }^{6}$ An additional cost of abandoning the peg in the second period could be introduced with little loss of generality. We let the currency board enjoy full discretion in the second period solely for analytic simplicity.
} 
The central bank then chooses then faces the first-period decision of whether or not to abandon the exchange rate peg. If the central bank abandons the peg, we assume that it suffers the penalty $\phi$ and makes its optimal exchange rate decision under discretion, which is derived in the previous section. The central bank loss function conditional on abandoning the currency board is then equal to that in (5) minus the abandonment penalty, $\phi$.

We next solve the central bank loss function given that it does not abandon the currency board. We again work backwards to ensure sub-game perfection. Because the central bank enjoys discretion in the second period regardless of its first-period decision, its decision concerning $e_{2}$ given $d_{2}$ is identical to that in equation (7). Consequently, equation (8) also determines the value of $d_{2}$ under the currency board.

Since the exchange rate is fixed in the first period under the currency board, $e_{0}=e_{1}$. By (10), the utility-maximizing choice of $C_{1}$ satisfies

$$
C_{1}=\left(\frac{e_{1} C_{2}}{\beta(1-\pi) e_{2}} \mid e_{1}=e_{0}\right)
$$

Given the implied second-period values, the loss function under the currency board can be obtained from (5). The central bank then abandons the currency board if and only if

$$
L \mid \text { discretion }<L \mid \text { currencyboard }
$$

where $L \mid$ discretion and L\&urrencyboard are equal to the central bank loss function conditional on abandoning and remaining in the currency board respectively in period $1 .^{7}$ The central bank loss function under the currency board regime then satisfies

$$
L=\min (L \mid \text { discretion, } L \mid \text { currencyboard }) \text {. }
$$

\footnotetext{
${ }^{7}$ Note that $L \mid$ discretion is not equivalent to the fully discretionary regime. It actually represents the offequilibrium action of deviating from the currency board when agents believe that the central bank will not deviate. The payoff from this action determines the parameters necessary for the currency board to be time consistent, even though the action never occurs in equilibrium.
} 


\subsection{Numerical results}

As the model does not have an analytical solution, we solve it numerically. Given parameters that satisfy the restrictions of the model, and guesses for $e_{1}$ and $l_{2}$, equations (6) through (10) can be used to solve for $C_{1}, C_{2}, e_{2}, d_{1}$, and $d_{2}$. Given the result of those "endogenous" variables, a system of two equations ((4) and (11)) and two unknowns ( $e_{1}$ and $l_{2}$ ) remain to be solved. The two equations are non-linear. We choose parameters that satisfy the attainment of a separating equilibrium and the cent ral bank's inflationary bias.

Since the model is highly stylized, we focus on the qualitative results of the model, and therefore the parameterization and calibration of the model are not emphasized. Nevertheless, we briefly detail our main assumptions here. We assume that the production function (3) is concave and a function of $\hat{e}_{t}{ }^{8}$ The values of the good and bad shocks are set to 1.05 and 0.45 , respectively. The probability of default, $\pi$, is set to $20 \%$. The monitoring $\operatorname{cost}, \delta$, is set equal to 0.40 . That value represents $21 \%$ of the dollar value of output when the firm receives the bad idiosyncratic shock and there is no devaluation. The value of the initial peso exchange rate, $e_{0}$, is normalized to 1 .

Let $\hat{\phi}$ represent the value of $\phi$ that leaves the central bank indifferent between remaining under the currency board and abandoning the board in favor of discretion in the first period, i.e. the value that satisfies (13) with equality. We find interior solutions for the model consistent with the parameter restrictions cited above for values of $\theta$ between 0.1 and 0.45. Our calculations of $\hat{\phi}$ within this range indicate that its value is positive for values of $\theta$ less than 0.3 and then turns positive and increases with $\theta$. However, even at our largest

\footnotetext{
${ }^{8}$ In particular, we assume that $A\left(\hat{e}_{t}\right)=A+B\left(\hat{e}_{t}+C\right)^{D}$.
} 
value of $\theta, \hat{\phi}$ is very small, only 0.13 percent of the absolute value of the central bank loss function. Consequently, we ensure that the currency board regime is an equilibrium outcome by assuming that $\phi \geq \hat{\phi}$ in our simulations. This implies that agents' exchange rate expectations are validated by the central bank choosing not to deviate and abandon the currency board in the first period. ${ }^{9}$

Our results are shown in Figure 2. For values of $\theta$ less than 0.263 , the central bank chooses depreciation in $e_{1}$ under discretion. Within this range, we obtain a higher risk premium, $d_{1} / l_{1}$, in the first period under discretion than under the currency board. The intuition behind this result is that defaults are more costly to the lender under discretion because of the reduced dollar-value of domestic output due to devaluation. There is also an increase in second-period borrowing, $l_{2}$, under discretion as the first-period devaluation pushes up first-period consumption, $C_{1}$, and reduces first-period service of outstanding debt.

We next turn to second-period values. Over $\theta$ values where a devaluation was chosen in the first period, $e_{2}$ is lower under discretion than under the currency board This reflects the impact of dollarized liabilities on the central bank's second-period decision. Because a greater amount of liabilities are carried into the second period under discretion, the central bank chooses less devaluation in that period. Indeed, for the lowest values of $\theta$, the central bank chooses a revaluation of the domestic exchange rate in the second period.

For values of $\theta$ which exceed 0.263 , we obtain almost opposite results. When the central bank places a high value on consumption, it chooses an exchange rate appreciation under discretion in the first period, and then a depreciation in the second period. This allows it to obtain higher second-period consumption than it would under the currency board.

\footnotetext{
${ }^{9}$ The calculations of $\hat{\phi}$ were left out of the text for space considerations, but are available on request.
} 
The overall impact can be seen in the plot of the central bank's loss function. There is little discrepancy between the two regimes. There is a slight preference for discretion in the range for low values of $\theta$, but the currency board does better for higher values of $\theta$. The surprisingly strong performance of the discretion regime is attributable to the fact that the central bank is concerned with the impact on firm balance sheets from devaluation due to their dollarized liabilities. This mitigates the central bank's inflation bias. ${ }^{10}$

\section{Equilibrium with foreign exchange rate shocks}

\subsection{Equilibrium values under discretion}

In this section, we extend the model to allow for shocks to the value of the dollar. Let $e_{t}$ now represent the peso-uro rate at time $t$, while $e_{t}^{\$}$ represents the dollar-eurorate at time $t$. The value of period $t$ output in dollars is equal to $e_{t}^{\S}\left(e_{t}\right)^{-1} Y_{i t}$. We maintain the small country assumption, so that all agents take the value of $e_{t}^{\S}$ as given. There are therefore two realizations of uncertainty in each period, idiosyncratic firm productivity and the dollar-euro exchange rate, $e_{t}^{\$}$. We assume that the dollar-eurorate follows a random walk, so that its value of the euro-dollar rate at time $t$ satisfies

$$
e_{t}^{\$}=e_{t-1}^{\$}+v_{t}
$$

where $v_{t}$ is a symmetric i.i.d. disturbance term with mean zero over the interval $[\underline{v}, \bar{v}]$.

All other aspects of the pure idiosyncratic model above are maintained. In particular, we retain equation (2) so that an unexpected depreciation of the domestic exchange rate still increases the value of firm output in pesos. However, we now posit that an unexpected depreciation of the domestic exchange rate decreases the value of firm output in euros.

\footnotetext{
${ }^{10}$ It should be stressed that the value of the central bank loss function need not be an indication of overall welfare per se. The central bank loss function includes the quadratic term corresponding to the centralbank's aversion to inflation. This may not match that held by the general public.
} 
We maintain the debt contract as the basic contract form. While it is true that optimal debt contracts would condition on observable aggregate shocks, we empirically observe both identifiable aggregate shocks and debt contracts in existence simultaneously, suggesting that the motivation for borrowing with a debt contract is attributable to an existing condition outside the scope of the model. ${ }^{11}$ Moreover, since the creditor is assumed to be risk neutral in our model, the optimal contract would fully condition on the aggregate shock, so that the creditor would insure the debtor as muchas possible. This would result in an equilibrium which was qualitatively similar to that in the idiosyncratic risk only model we derive above.

As before, we assume the parameter restrictions consistent with obtaining a separating equilibrium. In the presence of the foreign exchange rate shocks, this requires limits on the interval $[\underline{v}, \bar{v}]$. It is easy to see that if $v_{t}$ were unbounded, there would be positive probability states in which the peso value of the debt obligation went to zero. Under these conditions, bankruptcy would be avoided even by the firms receiving the poor idiosyncratic shock, eliminating the separating equilibrium.

To ensure sub-game perfection, we again solve the model backwards. The last decision is again that made by the central bank. At the time of the central bank's secondperiod decision, there are $(1-\pi)^{2}$ firms that received the good shock and $(1-\pi) \pi$ firms that received the bad shock. In addition, there is a realization of $e_{2}^{\$}$. Since the central bank is unable to depreciate its domestic currency sufficiently to make firms receiving the bad shock solvent, it takes as given the fact that only the $(1-\pi)^{2}$ firms that receive the good shock in period 2 will be solvent. Second-period consumption satisfies

\footnotetext{
${ }^{11}$ Similar issues arise in Cespedes et al. (2001), who conclude that the debt contract they consider is an approximation to the true optimal contract.
} 


$$
C_{2}=(1-\pi)^{2}\left[A\left(\hat{e}_{2}\right) g-\frac{e_{2}}{e_{2}^{\S}} d_{2}\right] \text {. }
$$

The central bank second-period decision problem is to choose $e_{2}$ to minimize (5) subject to (16) and the realization of $e_{2}^{\$}$. The optimal choice of $e_{2}$ satisfies

$$
e_{2}=e_{0}+\theta \beta(1-\pi)^{2} \frac{\left[A^{\prime}\left(\hat{e}_{2}\right) g-\left(e_{2}^{\$}\right)^{-1} d_{2}\right]}{2 C_{2}}
$$

Note that $\hat{e}_{2}$ will now not necessarily equal 0 , due to the foreign exchange rate shock. This implies that the central bank will be able to influence real values through its exchange rate decision. It also implies that the optimal choice of $e_{2}$ ex-post will now be a function of its expected value $E_{1}\left(e_{2}\right)$. We define $e_{2}^{*}$ as the choice of $e_{2}$ that solves (17). For analytic simplicity, we characterize $e_{2}^{*}$ as a function of $d_{2}, e_{2}^{\$}$, and $E_{1}\left(e_{2}\right)$

$$
e_{2}^{*}=e_{2}^{*}\left[d_{2}, e_{2}^{\$}, E_{1}\left(e_{2}\right)\right]
$$

As the foreign investor's payoff in dollars is now a function of the realization of $e_{2}^{\S}$, the individual firm's second-period contractual debt obligation, $d_{2}$, will be as well. The creditors' zero-profit constraint satisfies

$$
d_{2}=\left(\frac{1}{1-\pi}\right) l_{2}-\left(\frac{\pi}{1-\pi}\right)\left[E_{1}\left(\frac{e_{2}^{\S} A\left(\hat{e}_{2}^{*}\right)}{e_{2}^{*}}\right) b-\delta\right]
$$

where $\hat{e}_{2}^{*}=e_{2}^{*}-E_{1}\left(e_{2}^{*}\right)$.

We next solve for the first-period equilibrium values. Firms receiving the good shock in period 1 again choose $C_{1}$ to maximize their expected utility, defined in (1), subject to (16), (18), and (19), as well as the new first-period budget constraint, which satisfies 


$$
\left(\frac{e_{1}}{e_{1}^{\S}}\right)\left(l_{2}-d_{1}\right) \geq C_{1}-A\left(\hat{e}_{1}\right) g
$$

and $d_{1}$. By the zero-profit condition $d_{1}$ satisfies

$$
d_{1}=\left(\frac{1}{1-\pi}\right)-\left(\frac{\pi}{1-\pi}\right)\left[E_{0}\left(\frac{e_{1}^{\$} A\left(\hat{e}_{1}\right)}{e_{1}}\right) b-\delta\right]
$$

As above, individual firms are atomistic, and therefore take $E_{1}\left(e_{2}^{*}\right)$ as given when they make their maximization decisions.

Their first-order condition satisfies

$$
C_{1}=\left(\frac{e_{1}}{\beta(1-\pi) e_{1}^{\S}}\right) E_{1}\left(\frac{e_{2}^{\$} C_{2}}{e_{2}^{*}}\right)
$$

At the time of the central bank's first-period decision, $d_{1}$ and $e_{1}^{\S}$ are already

determined. The central bank chooses $e_{1}$ to minimize the expected value of its loss function in (5). Its first-order condition satisfies

$$
-\theta\left[\frac{1}{C_{1}} \frac{\partial C_{1}}{\partial e_{1}}+\beta E_{1}\left(\frac{1}{C_{2}} \frac{\partial C_{2}}{\partial e_{1}}\right)\right]+2 E_{1}\left(e_{2}-e_{0}\right) \frac{\partial E_{1}\left(e_{2}\right)}{\partial e_{1}}=0
$$

In the appendix, we derive the partial derivatives needed to solve (22) in terms of $e_{1}$ and $C_{1}$. Combined with first-period consumption in (21), this allows us to solve for $e_{1}$ and $C_{1}$ as a function of $d_{1}$ and the realization of $e_{1}^{\$}$. This system is solved numerically below.

\subsection{Equilibrium values under a currency board}

We next turn to the equilibrium under a currency board We again assume that if the central bank abandons the peg, it suffers the penalty $\phi$ and makes its optimal exchange rate 
decisions under discretion, which are derived in the previous section. If the central bank does not abandon the currency board, $e_{1}$ is set equal to the realization of $e_{1}^{\$}$.

Because the central bank enjoys discretion under the currency boardin the second period, its decision concerning $e_{2}^{*}$ given $d_{2}$ is identical to that in equation (18).

Consequently, equation (19) also determines the value of $d_{2}$.

However, since the exchange rate is fixed in the first period under the currency board, $e_{1}=e_{1}^{\$}$. By (21), the utility-maximizing choice of $C_{1}$ satisfies

$$
C_{1}=\frac{1}{\beta(1-\pi)} E_{1}\left(\frac{e_{2}^{\$} C_{2}}{e_{2}^{*}} \mid e_{1}=e_{1}^{\S}\right)
$$

The second-period values are thenagain easily obtained. Given these values, the loss function again satisfies (5). The central bank thenabandons the currency board if and only if (13) is satisfied The expected loss function under the currency board in period 0 satisfies

$$
L=E_{0}[\min (L \mid \text { discretion }, L \mid \text { currencyboard })]
$$

\subsection{Numerical results}

The solution to the model with aggregate shocks follows the model without shocks closely. However, since our endogenous variables are now functions of the realizations of the euro-dollar exchange rate, $e_{t}^{\$}$, they are now themselves random variables. To calculate the expected values of these variables numerically, we assume that the euro-dollar shock can take on three values with equal probability that are mean zero and symmetric :

$$
\begin{aligned}
& \mathrm{v}_{t} \in\left\{\mathrm{v}_{L}, \mathrm{v}_{M}, \mathrm{v}_{H}\right\}, \\
& \mathrm{v}_{L}=-\mathrm{v}_{H}, \mathrm{v}_{M}=0, \\
& \operatorname{prob}\left(\mathrm{v}_{L}\right)=\operatorname{prob}\left(\mathrm{v}_{M}\right)=\operatorname{prob}\left(\mathrm{v}_{H}\right)=1 / 3
\end{aligned}
$$


Given parameters that satisfy the restrictions of the model, and guesses for $e_{1}$ and $l_{2},{ }^{12}$ equations (16) - (19), (21) and (22) can be used to solve for $C_{1}, C_{2}, e_{2}, d_{1}$, and $d_{2}$. This leaves two non-linear equations $\left((20)\right.$ and (23) ) and twoendogenous terms $\left(e_{1}\right.$ and $\left.l_{2}\right){ }^{13}$ Our parameterization remains the same as above. The only new parameter to be introduced is the variance of the shock to the euro-dollar exchange rate, with is simply equal to $\operatorname{var}\left(v_{t}\right)=\sqrt{2 / 3} v_{H}$. For the benchmark parameterization, we set $v_{H}=7 \%$. As above, since the value of $\phi$ necessary to induce the central bank not to abandon the currency board is very low, we assume that $\phi$ is sufficiently high that the central bank never abandons the board. As in the last section, we primarily focus on the qualitative results of the model.

Our results for expected values at period 0 are shown in figure 4. Under discretion, the central bank is consistently expected to choose depreciation in $e_{1}$. Since the exchange rate under the currency board is fixed, this implies that the expected value of $e_{1}$ is higher under discretion. This corresponds to a higher expected risk premium, $d_{1} / l_{1}$. This leads to higher expected first-period consumption and second-period borrowing for all but the highest values of $\theta$ under discretion.

Turning to second-period values, the expected second-period exchange rate is lower under discretion than under the currency board. This again reflects the impact of dollarized liabilities on the second-period devaluation decision. Because a greater amount of dollarized liabilities are carried into the second period under discretion, the central bank chooses a lower level of devaluation in the second period For the lowest values of $\theta$, it appreciates $e_{2}$.

Similar to model above, the expected second period risk premium is higher for the bulk of admissible $\theta$ values under discretion because of the higher borrowing levels. The

\footnotetext{
${ }^{12}$ Note that these are now 3-by-1 vectors, one for each possible realization of the first-period foreign shock.

${ }^{13}$ To be precise, there are six equations and six unknowns, as (23) and (26) are 3-by-1 vectors.
} 
reason is again that the higher first-period consumption leads to higher borrowing levels, which increase lending losses under default.

The overall impact on the expected central bank loss function shows that the discretion model is expected to dominate the currency board for any value of $\theta$. This represents a stronger preference for discretion than the idiosyncratic-risk only model. This is intuitive as the ability to adjust would be expected to be more valuable in an environment that included aggregate shocks.

Figure 5 looks at expected and realized endogenous values subsequent to the realization of the first foreign exchange rate shock. We examine the realization of the central bank's choice of $e_{1}$ and the expected value of the central bank loss function for low, medium and high realizations of $e_{1}^{\S}$ over our range of $\theta$ values. For the low realization of the firstperiod dollar-eurorate, i.e. high dollar values, the centralbank chooses the largest levels of devaluation under discretion. Apparently, this choice is made to smooth first-period consumption. In contrast, for the high first-period realization, the central bank chooses to appreciate the peso-euro rate.

Looking at the central bank loss function, the discretion regime universally dominates over the currency board. The magnitudes of the disparity between these regimes, however, do differ systematically, as discretion is most dominant when the value of the dollar is high. For example, the difference is almost twice as large when the dollar is high than when the dollar is at its medium or low value for $\theta=0.3$. This discrepancy is intuitive as it is likely to be particularly important to be able to deviate from a peg to a high-valued dollar.

\section{Conclusion}

This paper examines the relative desirability of a currency board in the presence of dollarized liabilities and the possibility of firm default. In our model, dollarized liabilities 
positively impact the time-consistency problem faced by the monetary authority by increasing the cost of devaluations. The presence of dollarized liabilities would therefore be expected to reduce the relative desirability of a currency board. Our numerical results show that for our parame terization with only idiosyncratic shocks, the relative dominance of a currency board is ambiguous. However, with the introduction of shocks to the dollar-euro rate, the discretion regime unambiguously dominate $\mathrm{s}$ in terms of the central bank loss function. This latter result was somewhat surprising because the risk premium faced by firms under discretion was almost universally higher.

Some caveats to our results should be noted. First, while dollarization performs a positive role in our model by reducing the time-inconsistency problem faced by the central bank, it is clear that dollarization is perceived to pose a variety of difficulties empirically. This discrepancy may in part stem from features in developing country economies that are not captured in our model. For example, our model does not exhibit the large discrete devaluations with overshooting that often appear to accompany the abandonment of an exchange rate peg. In the presence of overshooting, the potential difficulties raised by the necessity of denominating a nation's liabilities in hard currency are likely to be increased.

A related issue concerns the severity of the time-inconsistency problem in our numerical results. As we limit ourselves to parameter values consistent with both solution of the model and maintenance of the separating equilibrium, the absolute levels of devaluation chosen in the paper appear to be relatively modest. This implies that the time-inconsistency problems considered in our numerical solutions may not be as severe as those experienced by central banks with very low credibility. Allowing for severe time-inconsistency problems could further favor the currency board

Finally, given that currency board abandonment might take place, the question of the optimal timing of such abandonment naturally arises, and clearly affects the relative 
desirability of adopting a currency board. That question is unaddressed in our model, as the central bank only considers abandoning the currency board in the first period. However, such a question could be addressed in a more stationary environment, such as that used by Rebelo and Vegh (2003) to examine the optimal timing of abandoning an exchange rate peg. We leave this question for future research.

\section{Acknowledgements}

We thank Joshua Aizenman, Richard Dennis, Sebastian Edwards, Reuven Glick, Jim Lothian, Federico Ravenna, and seminar participants for helpful comments. Edmund Chiang and Saumitra Saha provided excellent research assistance. 


\section{Appendix A. Solution with only idiosyncratic shock}

We first identify the parameter restrictions needed with only idiosyncratic shocks. The parameter restrictions needed to give the central bank an inflation bias, guarantee a separating equilibrium, and ensure solvency conditional on the good shock are respectively:

$$
\begin{gathered}
A^{\prime}(0) g-d_{2}>0 . \\
l_{2} \leq d_{1}-\left(e_{1}\right)^{-1} A\left(\hat{e}_{1}\right) b . \\
d_{2} \leq\left(e_{2}\right)^{-1} A\left(\hat{e}_{2}\right) g .
\end{gathered}
$$

By equations (6), (7), and (8), we can solve for $d_{2}$ :

$$
\left[l_{i 2}+\pi \delta-(1-\pi) d_{i 2}\right]\left(e_{0}+\frac{1}{2} \theta \beta(1-\pi)^{2}\left[\frac{A^{\prime}(0) g-d_{i 2}}{A(0) g-e_{2} d_{i 2}}\right]\right)=\pi A(0) b
$$

Totally differentiating

$$
\frac{\partial d_{i 2}}{\partial l_{i 2}}=\frac{2 e_{2}}{2(1-\pi) e_{2}-\left[l_{i 2}+\pi \delta-(1-\pi) d_{i 2}\right] \frac{\partial e_{2}}{\partial d_{i 2}}}>0
$$

given the restriction $A(0) \geq e_{2} A^{\prime}(0)$, which implies that $\partial e_{2} / \partial d_{i 2} \leq 0$.

Totally differentiating (7) with respect to $e_{2}$ and $l_{i 2}$ yields

$$
\frac{d e_{2}}{d l_{i 2}}=-\frac{g \theta \beta(1-\pi)^{2}\left(A(0)-e_{2} A^{\prime}(0)\right)}{2\left(A(0) g-e_{2} d_{i 2}\right)^{2}}\left(\frac{\partial d_{i 2}}{\partial l_{i 2}}\right)<0
$$

again, given the restriction $A(0) \geq e_{2} A^{\prime}(0)$.

We next solve for the partials necessary to derive the first-period central bank decision. By (6)

$$
\frac{\partial C_{2}}{\partial e_{1}}=-(1-\pi)^{2}\left[\frac{\partial e_{2}}{\partial e_{1}} d_{2}+e_{2} \frac{\partial d_{2}}{\partial e_{1}}\right]
$$

By (8) 


$$
\frac{\partial d_{2}}{\partial e_{1}}=\left(\frac{1}{1-\pi}\right) \frac{\partial l_{2}}{\partial e_{1}}+\left(\frac{\pi}{1-\pi}\right)\left(e_{2}\right)^{-2} A(0) b \frac{\partial e_{2}}{\partial e_{1}}
$$

By (4)

$$
\frac{\partial l_{2}}{\partial e_{1}}=\left(e_{1}\right)^{-2}\left[A(0) g-C_{1}\right]-\left(e_{1}\right)^{-1}\left[A^{\prime}(0) g-\frac{\partial C_{1}}{\partial e_{1}}\right]
$$

By (10)

$$
\frac{\partial C_{1}}{\partial e_{1}}=\frac{1}{\beta(1-\pi) e_{2}}\left(C_{2}+e_{1} \frac{\partial C_{2}}{\partial e_{1}}\right)-\frac{e_{1} C_{2}}{\beta(1-\pi)\left(e_{2}\right)^{2}} \frac{\partial e_{2}}{\partial e_{1}}
$$

Doing a first-order Taylor expansion around (17) yields the approximation

$\operatorname{By}(7)$

$$
\frac{\partial e_{2}}{\partial e_{1}}=-\frac{\theta \beta(1-\pi)^{2}}{2}\left\{\frac{1}{C_{2}} \frac{\partial d_{2}}{\partial e_{1}}-\frac{\left[A^{\prime}(0) g-d_{2}\right]}{2\left(C_{2}\right)^{2}} \frac{\partial C_{2}}{\partial e_{1}}\right\} .
$$

\section{Appendix B. Solutions with foreign exchange rate shock}

We first update the parameter restrictions needed in the presence of the foreign exchange rate shock. The parameter restrictions needed for devaluation to reduce the dollar value of output, give the central bank an inflation bias, guarantee a separating equilibrium, and ensure solvency conditional on the good shock are respectively:

$$
\begin{aligned}
& A^{\prime}\left(\hat{e}_{t}\right)<\left(e_{t}\right)^{-1} A\left(e_{t}\right) \\
& A^{\prime}\left(\hat{e_{t}}\right) g>d ; t=1,2 \\
& l_{2} \leq d_{1}-\left(\frac{e_{1}^{\$}}{e_{1}}\right) A\left(\hat{e}_{1}\right) b \\
& d_{2} \leq\left(\frac{e_{2}^{\$}}{e_{2}}\right) A\left(\hat{e}_{2}\right) g .
\end{aligned}
$$

We next solve for the partials needed to determine the optimal first-period central bank decision. By (16) 


$$
\frac{\partial E_{1}\left(C_{2}\right)}{\partial e_{1}}=E_{1}\left(\frac{\partial C_{2}}{\partial e_{2}^{*}} \frac{\partial e_{2}^{*}}{\partial e_{1}}\right)+\frac{\partial E_{1}\left(C_{2}\right)}{\partial d_{2}} \frac{\partial d_{2}}{\partial e_{1}}
$$

By (19)

$$
\frac{\partial d_{2}}{\partial e_{1}}=\left(\frac{1}{1-\pi}\right) \frac{\partial l_{2}}{\partial e_{1}}-\left(\frac{\pi b}{1-\pi}\right) E_{1}\left(\frac{e_{2}^{\$} A\left(\hat{e}_{2}\right)}{\left(e_{2}\right)^{2}} \frac{\partial e_{2}}{\partial e_{1}}\right)
$$

By (20)

$$
\frac{\partial l_{2}}{\partial e_{1}}=-\left(\frac{e_{1}^{\$}}{\left(e_{1}\right)^{2}}\right)\left[C_{1}-A\left(\hat{e}_{1}\right) g\right]+\left(e_{1}\right)^{-1}\left[\frac{\partial C_{1}}{\partial e_{1}}-A^{\prime}\left(\hat{e}_{1}\right) g\right]
$$

By (21)

$$
\frac{\partial C_{1}}{\partial e_{1}}=\frac{E_{1}\left(\frac{e_{2}^{\$} C_{2}}{e_{2}^{*}}\right)+e_{1} E_{1}\left(\frac{e_{2}^{\$}}{e_{2}^{*}} \frac{\partial C_{2}}{\partial e_{1}}-\frac{e_{2}^{\$} C_{2}}{\left(e_{2}^{*}\right)^{2}} \frac{\partial e_{2}^{*}}{\partial e_{1}}\right)}{\beta(1-\pi) e_{1}^{\$}}
$$

Doing a first-order Taylor expansion around (17) yields the approximation

$$
\frac{\partial e_{2}}{\partial e_{1}}=\frac{\left[e_{2}\left(e_{2}-e_{0}\right)-\frac{\theta \beta}{2}\right]\left(e_{2}^{\S}\right)^{-1} \frac{\partial d_{2}}{\partial e_{1}}}{\left[A^{\prime}\left(\hat{e}_{2}\right) g-\left(e_{2}^{\$}\right)^{-1} d_{2}-\left(\frac{e_{2}}{e_{2}^{\$}}\right) \frac{\partial d_{2}}{\partial e_{2}}\right]\left(e_{2}-e_{0}\right)+\frac{C_{2}}{(1-\pi)^{2}}-\frac{\theta \beta}{2}\left[A^{\prime \prime}\left(\hat{e}_{2}\right) g-\left(e_{2}^{\$}\right)^{-1} \frac{\partial d_{2}}{\partial e_{2}}\right]}
$$

where by (18)

$$
\frac{\partial d_{2}}{\partial e_{2}}=-\left(\frac{\pi b}{1-\pi}\right) E_{1}\left(\frac{e_{2}^{\$}}{\left(e_{2}\right)^{2}}\left[e_{2} A^{\prime}\left(\hat{e}_{2}\right)-A\left(\hat{e}_{2}\right)\right]\right)
$$




\section{References}

Aghion, P., Philippe B., Banerjee, A., 2001. Currency crises and monetary policy in an economy with credit constraints. European Economic Review 45, 1121-1150.

Caballero, R.J., Krishnamurthy, A., 2001. International and domestic collateral constraints in a model of emerging market crises. Journal of Monetary Economics 48, 513-548.

Calvo, G.A., Reinhart, C.M., 2002. Fear of floating. Quarterly Journal of Economics 117 (2), $379-408$.

Céspedes, L.F., Chang, R., Velasco, A., 2001. Balance sheets and exchange rate policy. mimeo, Rutgers University, December.

Céspedes, L.F., Chang, R., Velasco, A., 2002. Dollarization of liabilities, net worth effects, and optimal monetary policy. In: Edwards, S., Frankel, J. (Eds.), Preventing Currency Crises in Emerging Markets. University of Chicago Press.

Chang, R., Velasco, A., 2000. Financial fragility and the exchange rate regime. Journal of Economic Theory 92, 1-34.

de la Torre, A., Yeyati, E.L., Schmukler, S.L., 2003. Living and dying with hard pegs: the rise and fall of Argentina's currency board. forthcoming, Economia.

Dennis, R., 1999. Discretionary monetary policy with costly inflation. Economics Letters 65, 91-96.

Drazen, A., Masson, P.R., 1994. Credibility of policy versus credibility of policymakers. Quarterly Journal of Economics 109 (3), 735-754.

Edwards, S., 2002. The great exchange rate debate after Argentina. North American Journal of Economics and Finance 13, 237-252.

Edwards, S., Vegh, C., 1997. Banks and macroeconomic disturbances under predetermined exchange rates. NBER Working Paper no. 5977, March. 
Edwards, S., Edwards, A.C., 1987. Monetarism and Liberalization: The Chilean Experiment. University of Chicago Press, Chicago.

Frankel, J.A., Fajnzylber, E., Schmukler, S.L., Servén, L., 2001. Verifying exchange rate regimes. Journal of Development Economics 66, 351-386.

Ghosh, A.R., Gulde, A., Wolf, H.C., 2000. Currency boards: more than a quick fix? Economic Policy 15 (31), 269-335.

Jensen, M.C., 1986. Agency costs of free cash flow, corporate finance and takeovers. American Economic Review 76, 323-329.

Kamin, Steven B., (1988), “Devaluation, External Balance, and Macroeconomic Performance: A Look at the Numbers," Princeton Studies in International Finance, 62.

Oliva, M., Batiz, L.R., Sy, A.N.R., 2001. Discipline, signaling, and currency boards. Review of International Economics 9, 608-625.

Rivera-Batiz, Luis, A., Sy, A.N.R., 1997. Currency boards, credibility and macroeconomic behavior. IMF Working paper no. WP/00/97.

Rebelo, S., Vegh, C., 2003. When is it optimal to abandon a fixed exchange rate? forthcoming, Journal of International Money and Finance

Townsend, R., 1979. Optimal contracts and competitive markets with costly state verification. Journal of Economic Theory 21, 417-425. 


\section{Figure 1 \\ Timing of the Model}

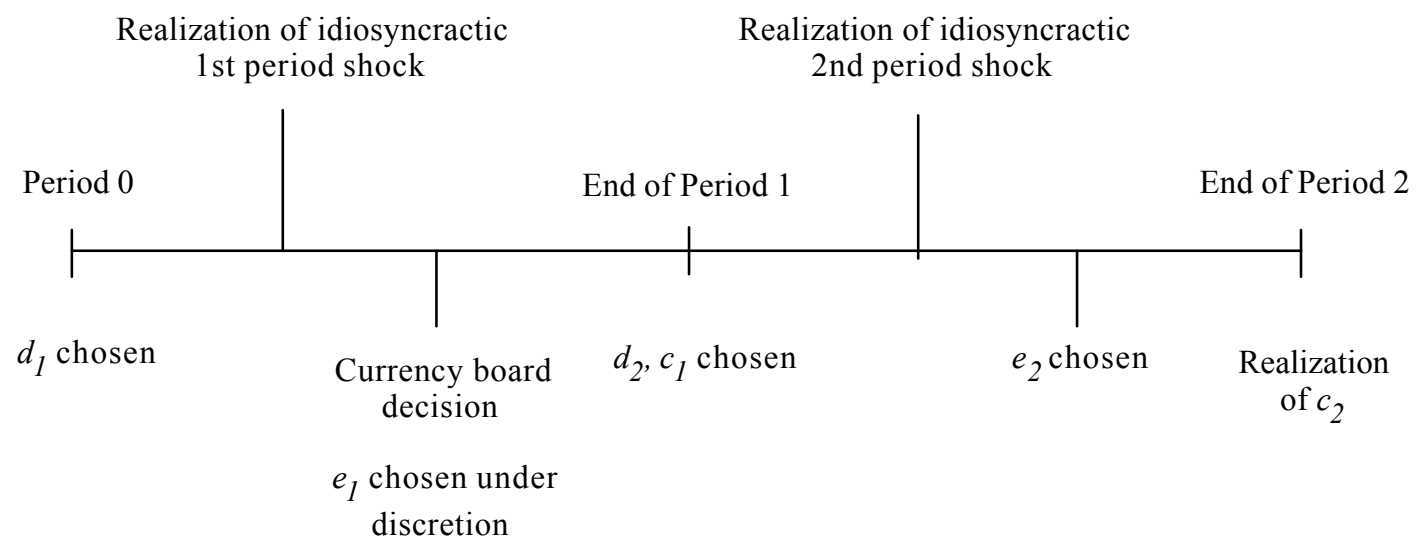


Figure 2

\section{Numerical Solutions with Idiosyncratic Shocks}
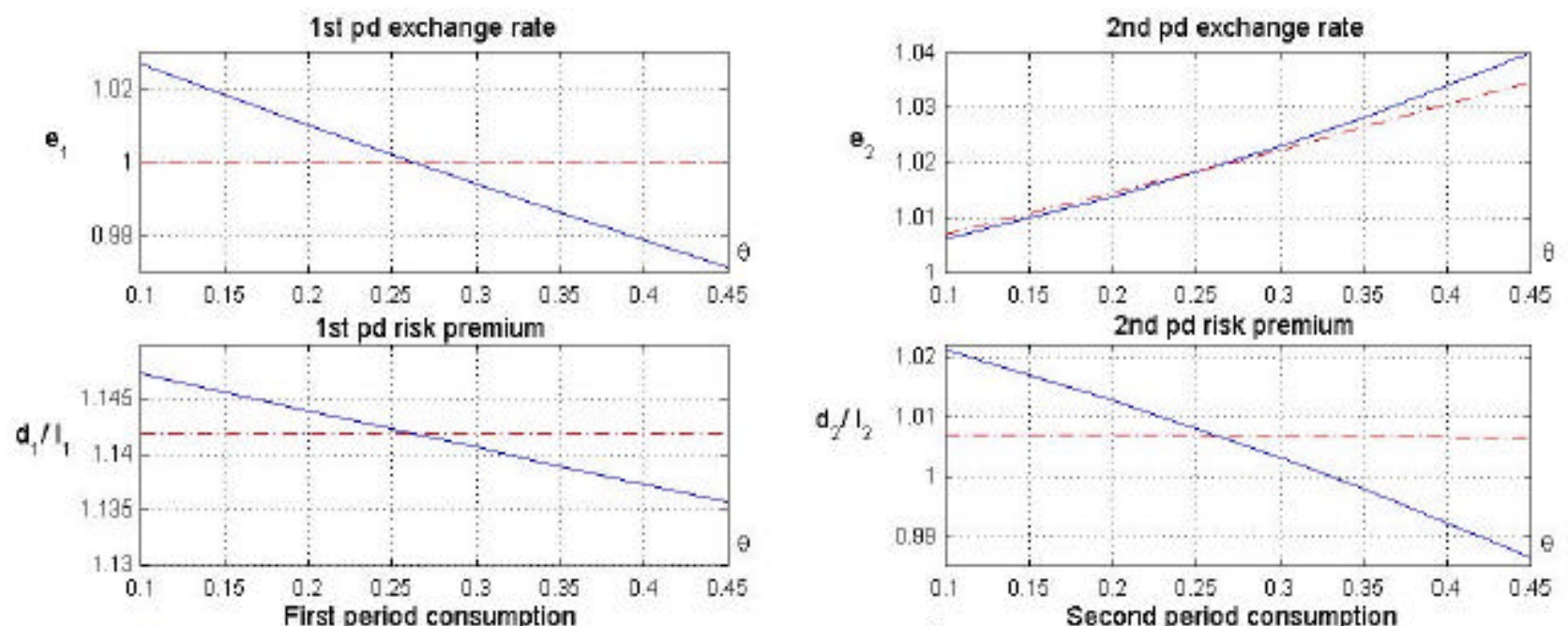

$\mathrm{d}_{2} / \mathrm{I}_{2}$

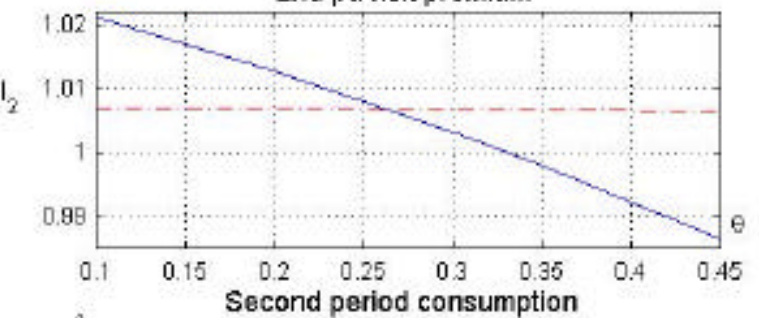

$c_{1}$
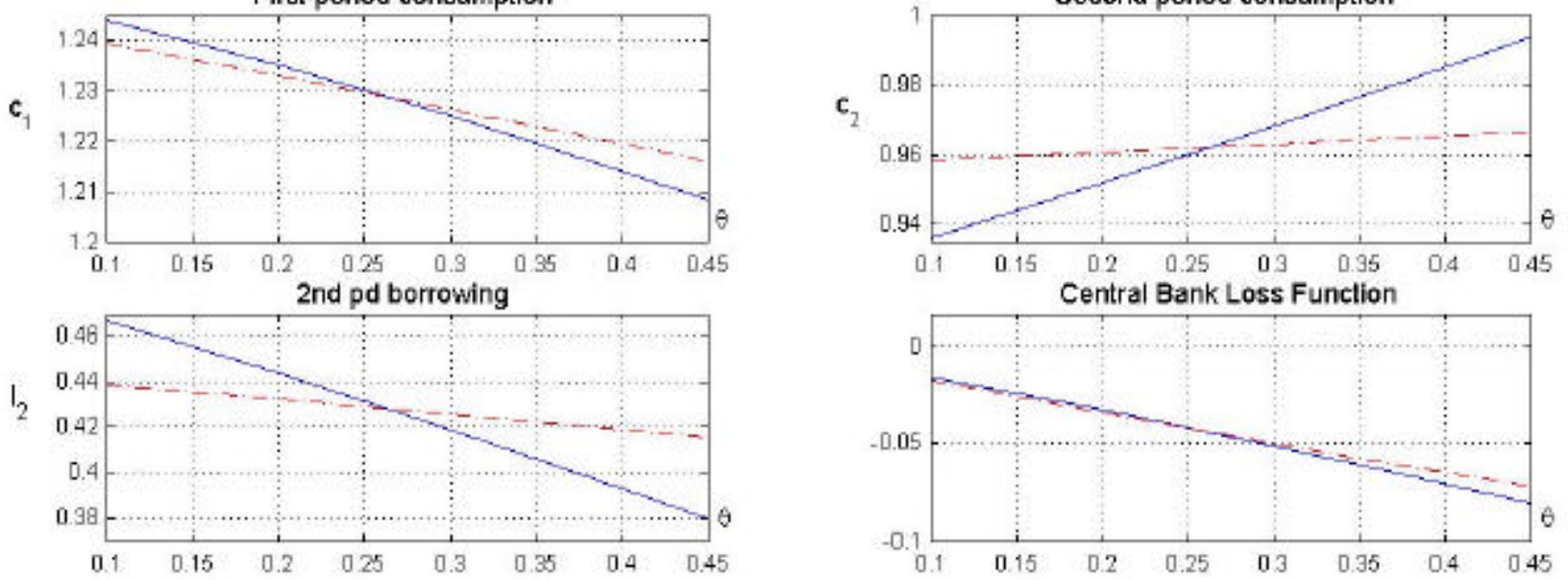

discretion

currency bd

Note: Values are plotted against $\theta$, the relative Central Bank weight on consumption. 


\section{Figure 3 \\ Timing of the Model $e_{1}^{\mathrm{s}}$ with Foreign Exchange Shocks}

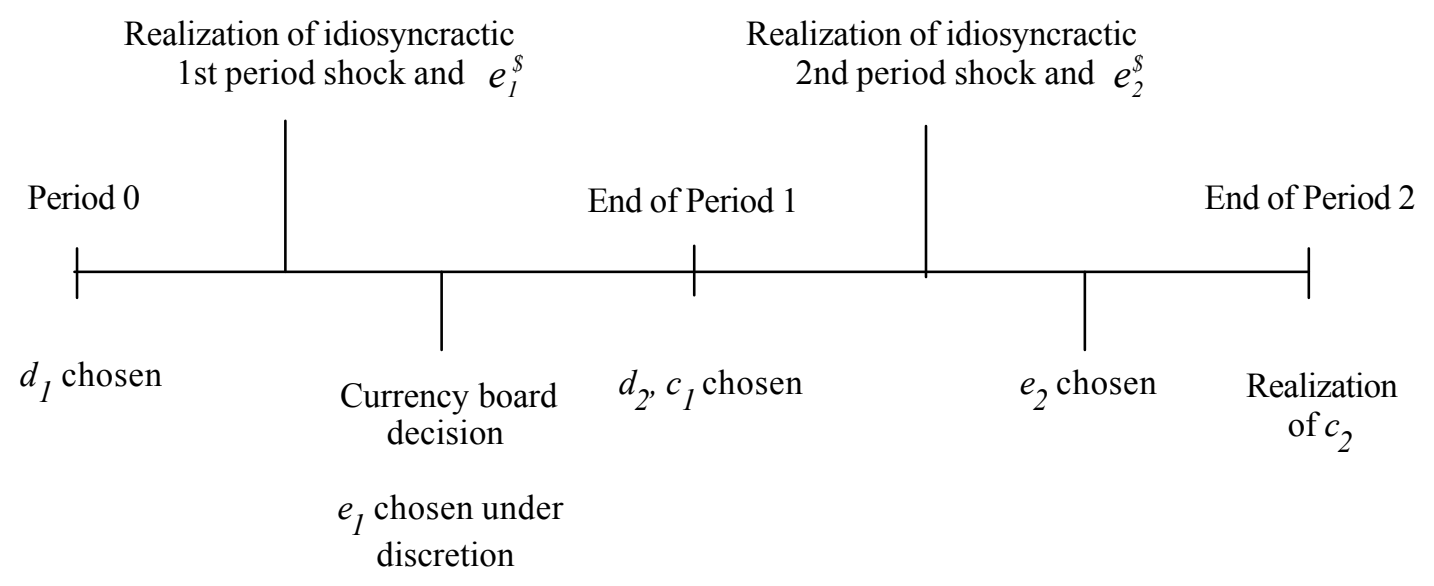




\section{Figure 4}

\section{Numerical Solutions for Expected Values with Idiosyncratic and Foreign Exchange Rate Shocks}
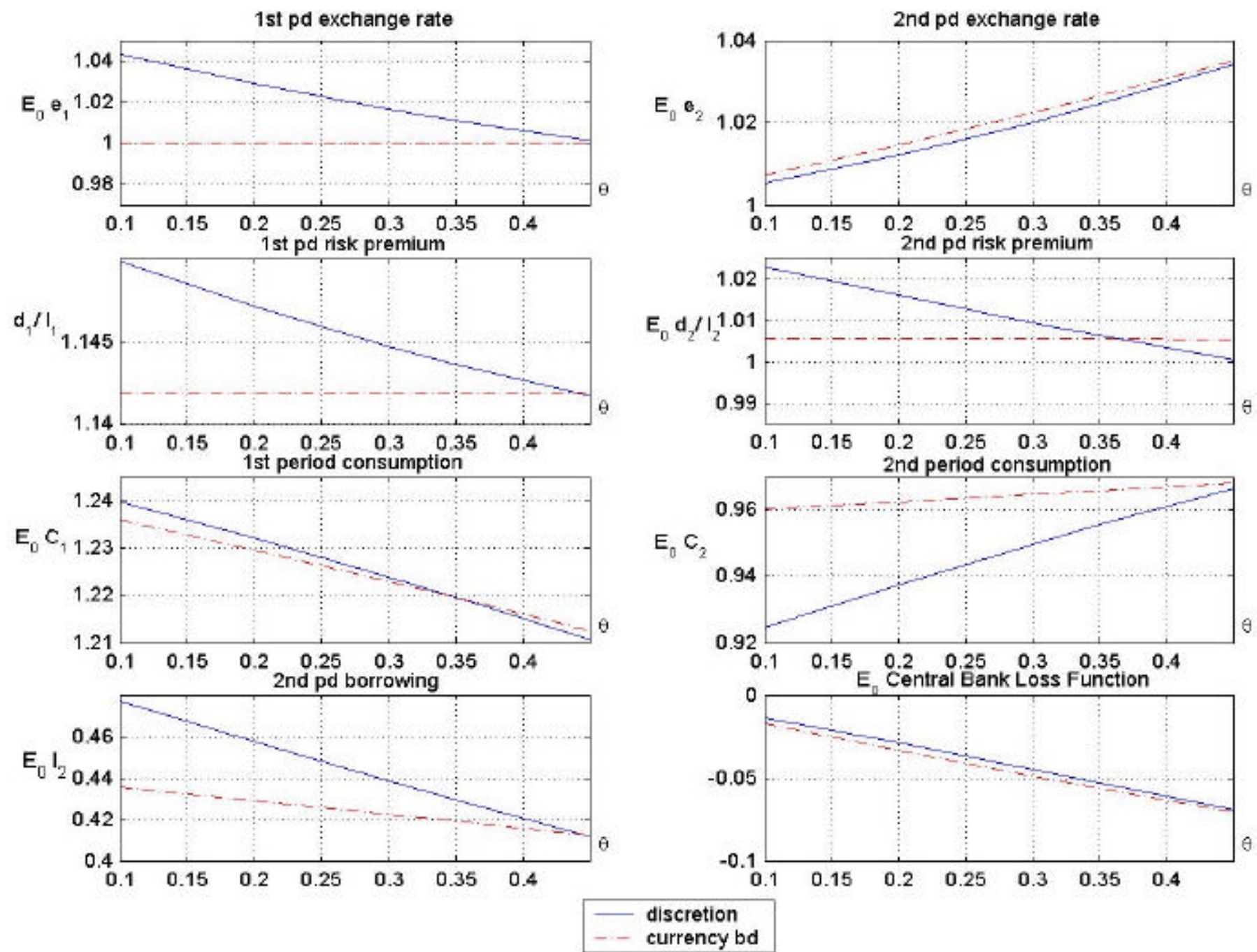

Jote: Values are plotted against $\theta$, the relative Central Bank weight on consumption. 
Figure 5

\section{Realized Values of Peso and Expected Central bank Loss Given First-Period Euro-Dollar Rate}
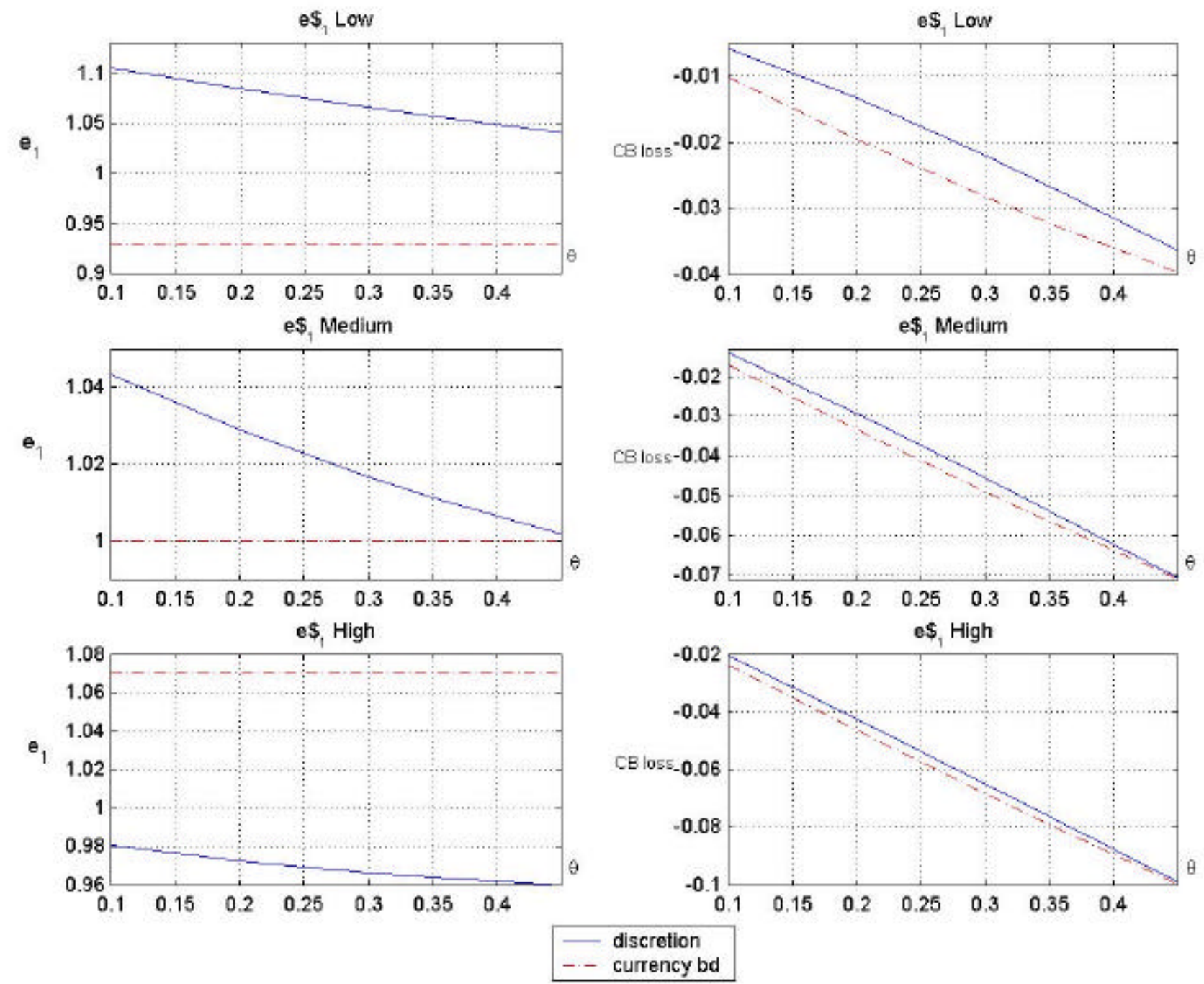